\title{
Antibiotic therapy of bacterial conjunctivitis - a practical approach
}

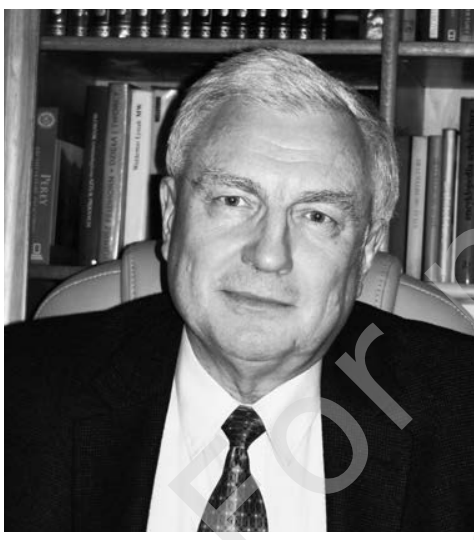

Marek E. Prost ${ }^{1,2}$

'Ophthalmology Clinic, Military Institute of Aviation Medicine, Warsaw Head: Radosław Różycki, MD, PhD

${ }^{2}$ Children's Ophthalmology Center in Warsaw Head: Ewa Oleszczyńska-Prost, MD, PhD

H I G H L I G H T S

In bacterial conjunctivitis, IV-generation and then III-generation fluoroquinolones should be regarded as the first-line drugs, due to the highest treatment effectiveness, penetration into the conjunctiva and the lowest risk of developing antibiotic resistance.

\section{ABSTRACT}

The most common cause of ophthalmological consultations in an ophthalmological clinics are conjunctivitis, often caused by bacteria. The main form of its treatment is topical antibiotic therapy. The paper presents the current possibilities of treatment of conjunctivitis, with particular emphasis on the problem of development of the antibiotic resistance and the practical principles of antibiotic therapy. In the light of current knowledge, the best results in the treatment of bacterial conjunctivitis are achieved by the use of IV-and then III-generation of fluoroquinolones. These drugs have the best spectrum of action, and additionally, they have a very good penetration into the conjunctiva and are at the lowest risk of developing antibiotic resistance.

Key words: antibiotics, antibiotic resistance, fluoroquinolones, aminoglycosides, macrolides, conjunctivitis 


\section{INTRODUCTION}

Bacterial inflammation of the ocular surface accounts for approximately $15 \%$ of the causes of eye care visits to ophthalmologists and is one of the most common treated conditions $[1,2]$. Antibiotics are the main group of drugs used for these ailments. Currently, the number of ocular antibiotic preparations at the ophthalmologist's disposal is quite large and they have a wide range of possibilities to adapt the therapy to the patient's condition. However, the widespread use of drugs from this group, not only in ophthalmic indications, has resulted in the rapid development of bacterial strains resistant to antibiotic therapy in recent years, which significantly limits the effectiveness of treatment.

\section{CONJUNCTIVITIS}

Conjunctivitis involves the development of inflammation in the eyelid and eyeball conjunctiva. This results in severe congestion and swelling of the conjunctiva and eyelids as well as purulent, serous or mucopurulent discharge in the conjunctival sac and on the edges of the eyelids. In some cases, papules and warts may appear in the conjunctiva, but rarely these inflammatory conditions are accompanied by corneal lesions (most often in viral and chlamydial inflammations).

Conjunctivitis by cause is divided into:

- infectious

- non-infectious

- accompanying other diseases.

Infectious conjunctivitis can be caused by bacteria, viruses, chlamydiae and very rarely by protozoa and fungi. However, bacteria are by far the most common cause, mainly staphylococci (Staphylococcus aureus, Staphylococcus epidermidis), streptococci (Streptococcus pyogenes, Streptococcus pneumoniae, Streptococcus viridans), less commonly Gram(-) bacilli (Haemophilus influenzae), Gram(-) granules (Moraxella lacunata) and chlamydiae (Chlamydia trachomatis). The least frequent causes of infectious inflammation are Serratia, Proteus, Enterobacter, Klebsiella, Corynebacterium, as well as Escherichia coli and Pseudomonas aeruginosa [1-4].

\section{ANTIBIOTIC THERAPY}

The primary form of treatment for bacterial conjunctivitis is antibiotic therapy. Its main goals are:

- shortening the duration of the disease in relation to the natural course of the infection and thus a faster return to regular life

- reducing the likelihood of complications

- decreasing the possibility of the patient infecting other persons.
Due to the low reliability of bacterial culture results (incidental bacteria from the eyelid skin are most frequently detected), high costs of the test and short duration of inflammation, targeted therapy is usually not used, but broad-spectrum antibiotics acting on both $\operatorname{Gram}(+)$ and Gram(-) bacteria. In Poland, inflammatory conditions caused by chlamydia are very rarely diagnosed; therefore it is desirable that the antibiotics used should also affect them [5]. The effectiveness of antibiotics is also greatly improved by their good penetration into the conjunctiva and cornea. They should also be bactericidal rather than bacteriostatic, as this reduces the possibility of developing antibiotic resistance. Because the reliability of the drugs decreases with more frequent use throughout the day, they should be administered as infrequently as possible, preferably twice a day. The issue of preservative content seems less important since antibiotics, unlike long-term medications (e.g., antiglaucoma drugs), are administered approximately for 1-2 weeks.

In eye diseases, the most commonly used antibiotics are aminoglycosides and fluoroquinolones. Both groups act on both Gram(+) and Gram(-) bacteria. Aminoglycosides bind to the bacterial ribosome and disrupt the function of ribosomal RNA in the ribosome, leading to impaired reading of genetic information and inhibition of bacterial protein synthesis [6]. This group is effective against staphylococci, including Staphylococcus aureus (the exception being some methicillin-resistant Staphylococcus aureus (MRSA), as well as against Gram(-) bacteria, especially Haemophilus, Enteriobacteriaceae, and Pseudomonas. However, their activity against streptococci is limited.

Fluoroquinolones inhibit bacterial enzymes: topoisomerase II (DNA gyrase) and topoisomerase IV, which inhibits DNA replication and synthesis, and consequently leads to bacterial death. Activity against Gram(-) bacteria is primarily associated with topoisomerase II inhibition, while against Gram(+) bacteria it is related to tropoisomerase IV inhibition. The $2^{\text {nd }}$ generation drugs inhibit topoisomerase II, whereas the $3^{\text {rd }}$ and $4^{\text {th }}$ generation antibiotics act on both enzymes, which makes them more effective [3, 7]. As a result, fluoroquinolones are characterized by potent activity against Gram(-) bacteria (Haemophilus, Salmonella, Neisseria, Enterobacteriaceae, Pseudomonas), whereas their activity against Gram(+) bacteria differs depending on the generation. $2^{\text {nd }}$ generation fluoroquinolones (ciprofloxacin, ofloxacin, and lomefloxacin) have weak activity against $\operatorname{Gram}(+)$ bacteria, while the $3^{\text {rd }}$ generation (levofloxacin) works better against Gram(+) microorganisms. On the other hand, the $4^{\text {th }}$ generation fluoroquinolones (gatifloxacin, moxifloxacin and bezyfloxacin) are highly active against both Gram(-) and Gram(+) bacteria and additionally against anaerobic bacteria, and moxifloxacin also against chlamydiae $[3,5-7]$. 
Of the other antibiotics, only azithromycin, an antibiotic from the macrolide group, is used in the treatment of conjunctivitis. Macrolides are bacteriostatic antibiotics, but at higher concentrations (e.g., azithromycin at 1.0-1.5\%) they are bactericidal [6]. Azithromycin is active against $\operatorname{Gram}(+)$ and Gram(-) bacteria, anaerobes and chlamydiae, with the highest efficacy against bacteria of the Haemophilus and Moraxella genera, whereas its activity against staphylococci (especially against MRSA strains), streptococci (Streptococcus pneumoniae, pyogenes, and viridans) and Neisseria gonorrhoeae is limited due to the rapid development of acquired resistance. Enterococcus and Pseudomonas aeruginosa strains are insensitive to azithromycin $[5,6]$.

\section{PENETRATION}

Antibiotics vary in their ability to penetrate different parts of the eye. Moxifloxacin, gatifloxacin, and azithromycin are the most effective in terms of penetration into the conjunctiva and cornea, while moxifloxacin and levofloxacin work best in terms of penetration into the aqueous and vitreous humors (tab. 1).

On the other hand, azithromycin is very well absorbed into the conjunctiva and somewhat less well into the cornea; in addition, the elimination time from these tissues is quite long (long tissue half-life), which means that its therapeutic concentration (above MIC90) can persist for up to 7 days. Azithromycin is captured, transported and released by neutrophil granulocytes and phagocytes and is therefore actively transported to sites of infection. In the treatment of corneal inflammation (ulceration), care must be taken to ensure that the used antibiotic also penetrates well into the aqueous humor in the anterior chamber of the eye (tab. 2). In intraocular inflammatory conditions, the penetration of antibiotics into the anterior chamber or vitreous humor given in eye drops is much greater (tab. 2).

\section{ANTIBIOTIC RESISTANCE IN OPHTHALMIC TREATMENT}

Antibiotic resistance has already become such a serious problem that many countries have established programs and institutions to monitor and prevent the development of antibiotic resistance in bacteria. In Poland, this was the National Program for Antibiotic Protection carried out between 2011 and 2020 and implemented with funding from the health program of the Minister of Health. The phenomenon of antibiotic resistance develops when bacteria come into contact with a drug used in sublethal dos-

\section{TABLE $(1$}

Concentrations of various antibiotics in the conjunctiva, cornea, aqueous and vitreous humors after topical application as eye drops (based on [3]).

\begin{tabular}{|c|c|c|c|c|}
\hline Antibiotic & $\begin{array}{l}\text { Antibiotic concen- } \\
\text { tration in the cornea } \\
(\mu \mathrm{m} / \mathrm{g})[3]\end{array}$ & $\begin{array}{l}\text { Antibiotic concentra- } \\
\text { tion in the conjunctiva } \\
(\mu \mathrm{m} / \mathrm{g})[8.9]\end{array}$ & $\begin{array}{c}\text { Antibiotic concentration in } \\
\text { the aqueous humor ( } \mu \mathrm{m} / \\
\mathrm{ml})[10-16]\end{array}$ & $\begin{array}{c}\text { Antibiotic concentration in } \\
\text { the vitreous humor }(\mu \mathrm{m} / \mathrm{ml}) \\
{[12.15]}\end{array}$ \\
\hline Moxifloxacin & 48.5 & 18.0 & $1.74-4.92$ & 0.28 \\
\hline Gatifloxacin & 15.7 & 2.65 & $0.48-0.94$ & \\
\hline Levofloxacin & 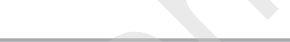 & 2.54 & 2.89 & 0.03 \\
\hline Ciprofloxacin & $D^{2}$ & 2.34 & 2.16 & 0.08 \\
\hline Ofloxacin & 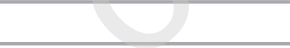 & 1.23 & $0.28-1.9$ & $0.07-0.25$ \\
\hline Lomefloxacin & & & $0.23-1.54$ & \\
\hline Norfloxacin & & & 0.10 & \\
\hline Tobramycin & & 1.68 & & \\
\hline Azithromycin & 9.28 & 40.4 & $<0.1$ & \\
\hline
\end{tabular}

\section{TABLE 2}

Concentrations of various fluoroquinolones in the aqueous and vitreous humors in intraocular inflammation after topical application as eye drops (based on [15]).

\begin{tabular}{l|c|c|c|c}
\multicolumn{1}{c|}{ Antibiotic } & $\begin{array}{c}\text { Antibiotic concentration } \\
\text { in the aqueous humor } \\
(\boldsymbol{\mu} \mathbf{m} / \mathbf{g})\end{array}$ & $\begin{array}{c}\text { Antibiotic concentration } \\
\text { in the inflamed aqueous } \\
\text { humor }(\boldsymbol{\mu m} / \mathbf{g})\end{array}$ & $\begin{array}{c}\text { Antibiotic concentration } \\
\text { in the vitreous humor } \\
(\boldsymbol{\mu m} / \mathbf{m I})\end{array}$ & $\begin{array}{c}\text { Antibiotic concentration } \\
\text { in the inflamed vitreous } \\
\mathbf{h u m o r}(\boldsymbol{\mu m} / \mathbf{m I})\end{array}$ \\
\hline Moxifloxacin & 4.92 & 43.3 & 0.28 \\
\hline Lomefloxacin & 3.54 & 1.19 & 0.0013 \\
\hline Levofloxacin & 2.89 & 9.41 & 0.03 \\
\hline Ciprofloxacin & 2.16 & 3.65 & 0.08 & 0.03 \\
\hline Ofloxacin & 1.9 & 2.69 & 0.25
\end{tabular}


es $[5,17]$. This happens when the used antibiotic does not have an effect on a given bacterial strain, has low penetration capacity to inflammatory foci and when patients take it against the physician's recommendations (low reliability of drug use) or when inappropriate dosage is recommended (tab. 3). Under these conditions, bacteria develop various mechanisms leading to the development of antibiotic resistance. As a result, at present there are already bacterial strains (e.g. causing tuberculosis, salmonellosis, nosocomial infections) resistant to all currently available antibiotics. A major problem is the rapid growth of MRSA (methicillin-resistant Staphylococcus aureus), which is poorly susceptible or resistant to even the strongest antibiotics $[1,5$, 18]. These bacteria are the most common cause of in-hospital infections.

\section{TABLE 3}

Conditions for the development of antibiotic resistance.

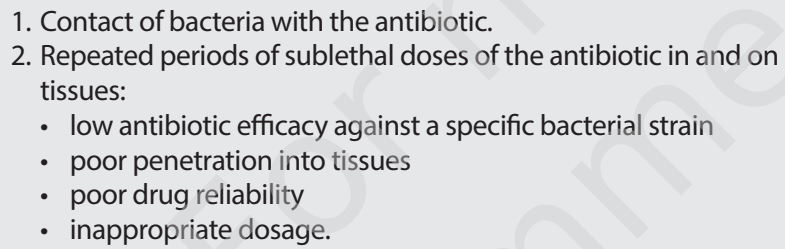

One antibiotics group which develop resistance the least frequently are the aminoglycosides, especially if we take into account the long time of their use in medicine (streptomycin since 1944, gentamicin since 1963, tobramycin since 1967, amikacin since 1972). In this group, the mechanism of resistance develops as a result of decreased permeability of the bacterial wall to the drug, the formation of bacterial enzymes that modify the structure of the antibiotic and prevent it from binding to ribosomes, and because of mutations in bacterial ribosomes, as a result of which the aminoglycoside cannot bind to them. In the case of aminoglycosides, cross-resistance to other drugs from this group is rarely observed, which is common in other groups $[1,6,17]$.

Antibiotic resistance of fluoroquinolones develops as a result of spontaneous mutations in the genes encoding topoisomerase II (DNA gyrase) and topoisomerase IV - enzymes whose inhibition is the basis of the antibacterial activity of these antibiotics. It may also result from inhibition of drug penetration to the bacterial interior (via excessive action of a drug pump transporting drugs outside the bacterial cell) $[6,7,17]$. In the case of $2^{\text {nd }}$ generation fluoroquinolones one mutation is usually sufficient for the development of antibiotic resistance, whereas in the case of $3^{\text {rd }}$ and $4^{\text {th }}$ generation drugs two mutations are necessary. Unfortunately, the occurrence of the first mutation facilitates the development of the second one $[6,17]$. Therefore, the development of antibiotic resistance is quite common in the case of drugs from the group of fluoroquinolones and represents a major problem. It develops particularly well against $\mathrm{Gram}(+)$ bacteria and therefore the $2^{\text {nd }}$ generation drugs have very little effect on these microorganisms. This is also a cross-reaction, so the administration of $2^{\text {nd }}$ and $3^{\text {rd }}$ generation fluoroquinolones also facilitates the development of resistance to $4^{\text {th }}$ generation drugs (only one mutation is needed, not two) $[5,11,17]$. Activation of the drug pump (removal of antibiotics outside the bacterial cell) hinders the penetration of not only fluoroquinolones but also other classes of antibiotics into the bacteria, thus increasing cross-resistance $[6,19]$.

With macrolides, antibiotic resistance develops relatively quickly and easily. Its most common mechanism involves the induction of enzymes that alter the structure of bacterial ribosomes. It is usually cross-reactive and occurs with both macrolides and lincosamides [6].

The development of antibiotic resistance most often occurs during the general administration of antibiotics, but even topical application of eye drops and ointments can lead to the development of resistant bacterial strains. This is especially true for fluoroquinolones, for which a single administration of ocular preparations may be sufficient to develop antibiotic resistance [20]. In contrast, there is conflicting data as to whether long-term conjunctival bag application of antibiotics increases the risk of resistance development $[19,21]$.

\section{HOW TO USE ANTIBIOTICS IN CONJUNCTIVITIS?}

Broad-spectrum antibiotics for both Gram(+) and Gram(-) bacteria are used in the treatment of conjunctivitis because of the already mentioned limited value of bacteriological tests in this condition. Considering the bacterial strains that most frequently cause inflammation, an antibiotic effective against staphylococci (including MRSA), streptococci, Haemophilus and Moraxella should be used for their treatment. Anthelmintic activity is also desirable, as these inflammations are much more common in Poland than they are diagnosed. Aminoglycosides act on staphylococci (although not on all MRSA strains), weakly on streptococci and strongly on Haemophilus and Moraxella. $2^{\text {nd }}$ generation fluoroquinolones are not very effective against staphylococci (especially MRSA) and streptococci, but this depends on the time of introduction of the drug to the market due to the rapid progress of antibiotic resistance against Gram(+) strains. These drugs have potent activity against Gram(-) bacteria, including Haemophilus and Moraxella. The most effective against $\operatorname{Gram}(+)$ bacteria are fluoroquinolones of the $3^{\text {rd }}$ and especially the $4^{\text {th }}$ generation. They also show the strongest activity against $\operatorname{Gram}(-)$ bacteria. Moreover, moxifloxacin is also effective against chlamydia. 
Macrolides (azithromycin) are weak against staphylococci and streptococci, and their potency decreases rapidly due to the rapid development of antibiotic resistance, while they are effective against Haemophilus and Moraxella, as well as chlamydiae.

Penetration of antibiotics into the conjunctiva is greatest for azithromycin, levofloxacin, and moxifloxacin. The latter is also characterized by the greatest penetration into the cornea, which is important if corneal infiltrates are present. Lower intraocular penetration is seen with gatifloxacin, levofloxacin, and ciprofloxacin. The use of antibiotics in conjunctivitis should also take into account the development of antibiotic resistance. In the case of fluoroquinolones, prescribing less effective second-generation drugs results in more frequent development of the first mutation, which facilitates the occurrence of the second mutation in the case of the third and fourth generations, thus leading to a more rapid decrease in the effectiveness of the newest group of antibiotics. Preservative-free ocular antibiotics include azithromycin (manufactured in single-use minims) and moxifloxacin (which is both an active ingredient and a preservative).

Thus, in terms of efficacy against the bacteria that most frequently cause conjunctivitis, the really effective antibiotics are the $3^{\text {rd }}$ and especially the $4^{\text {th }}$ generation fluoroquinolones, as they have a strong effect on staphylococci (including MRSA strains), streptococci and Haemophilus and Moraxella, and moxifloxacin also on chlamydiae [22, 23]. Other antibiotics have no effect on most of them, especially $\operatorname{Gram}(+)$. In order to avoid the development of antibiotic resistance, it is advisable to use first of all fluoroquinolones of the $4^{\text {th }}$ generation, as they eliminate the most bacteria and the risk of resistance development (the need of two mutations) is lower [17]. Because of the reliability of use, the best would be azithromycin and tobramycin, which can be administered twice a day. $4^{\text {th }}$ generation fluoroquinolones should be administered into the eye 3 times a day and other antibiotics 4 times a day.

To conclude, it should be stated that the best antibiotics in the treatment of conjunctivitis are fluoroquinolones of the $3^{\text {rd }}$ and especially the $4^{\text {th }}$ generation, providing both the best treatment effectiveness, the best penetration into the conjunctiva and the lowest risk of developing antibiotic resistance. However, they should be used in moderation (tab. 4).

They should be prescribed only when we the physician is certain to be dealing with bacterial conjunctivitis or as a prophylaxis for bacterial infection [5, 23, 24]. Therapy should begin with prescribing a $3^{\text {rd }}$ or $4^{\text {th }}$ generation fluoroquinolone as the most effective antibiotic acting on all bacteria causing conjunctivitis and posing the least risk of developing antibiotic resistance. Treatment should not last

\section{TABLE}

Practical rules for using antibiotics in eye drops for ocular surface disease.

1. Use the latest generation of antibiotics:

- they have the widest spectrum of action and best efficacy

- they pose the lowest risk of developing antibiotic resistance.

2. Do not prescribe antibiotics unless necessary.

3. Never use gradual withdrawal of antibiotics.

4. Avoid prolonged antibiotics treatment (more than 7 days).

longer than 7 days (typical bacterial conjunctivitis usually does not last longer) [23]. Prolonging it (sometimes antibiotics are prescribed for months) only increases the risk of developing antibiotic resistance. If the drug does not resolve the inflammatory symptoms, it means that the bacteria are not sensitive to the antibiotic used or we are dealing with another, non-bacterial cause of inflammation. A gradual withdrawal of the drug should also not be recommended, because then there are long periods of sublethal doses of the antibiotic in the tissues and on their surface, which creates ideal conditions for bacteria to develop antibiotic resistance. The treatment regimen for bacterial conjunctivitis is shown in figure 1 .

\section{CONCLUSIONS}

All the groups described are broad-spectrum antibiotics, but their efficacy varies between different groups of bacteria - the highest against $\operatorname{Gram}(-)$ bacteria and the lowest against $\operatorname{Gram}(+)$ bacteria. The best efficacy against Gram(+) bacteria in these groups is achieved by fluoroquinolones of the $4^{\text {th }}$ generation, while the $3^{\text {rd }}$ generation is slightly weaker.

This conclusion and the resulting regimen presented here differ from the treatment standards used to date in the treatment of conjunctivitis, which assume starting the treatment with older, less effective antibiotics as first-line therapy and prescribing the newest chemotherapeutic agents only if the first drug is ineffective or the disease is severe. Under this scheme, patients will be treated with antibiotics that do not work against most of the bacteria that cause conjunctivitis, which could lead to the more rapid development of bacterial strains resistant even to the latest fluoroquinolone antibiotics, currently our best weapon in treating ocular surface inflammation.

There are high hopes associated with the introduction of a new group of antibiotics, the so-called acylated depsipeptides (ADEP). They act by binding to the protease of the bacterial cell wall, which leads to the degradation of its proteins. Thus, ADEPs have a different mechanism of action than other groups of antibiotics, and thus a different efficacy on bacteria [25]. 


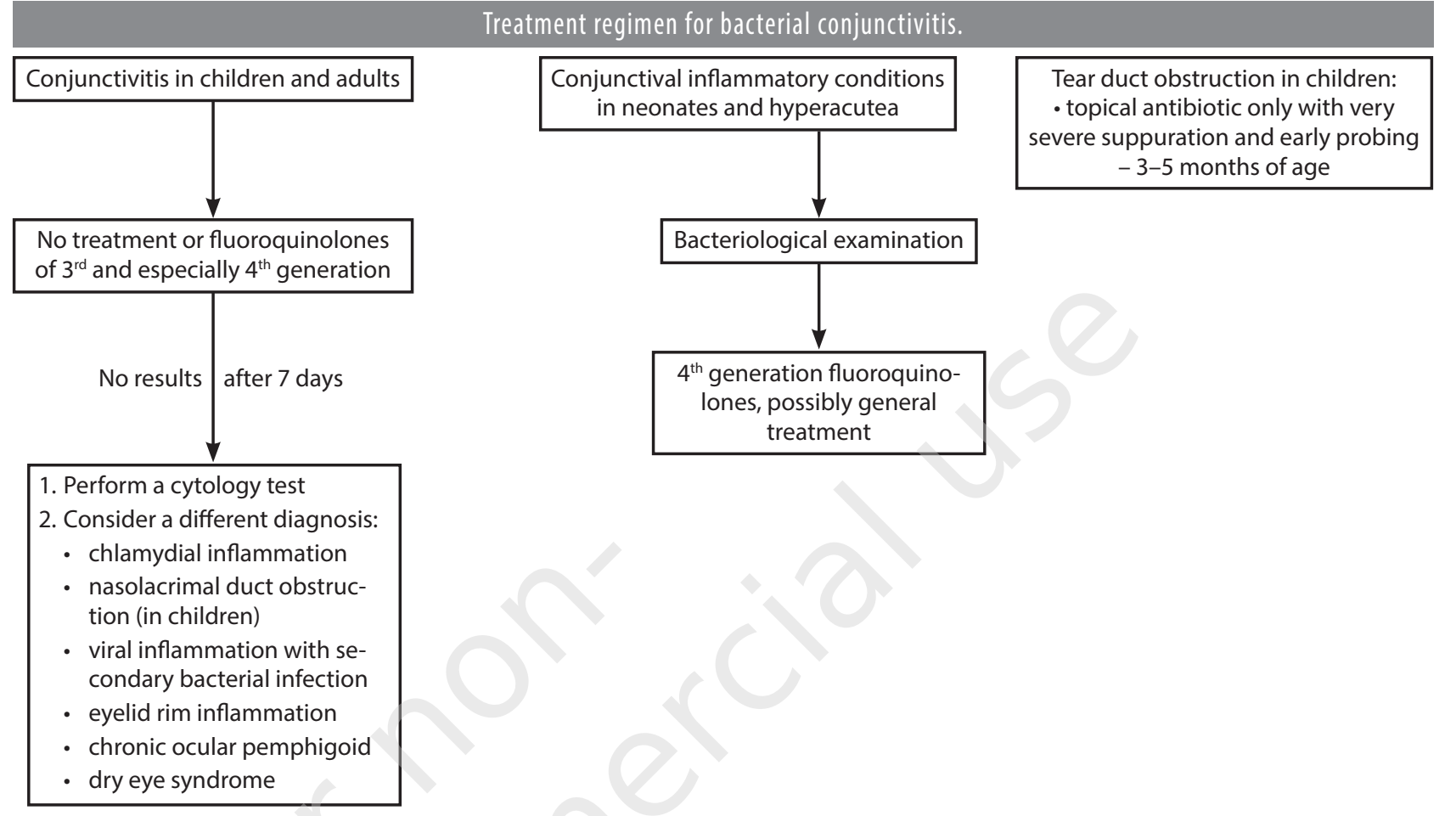

\section{CORRESPONDENCE}

Prof. Marek E. Prost, MD, PhD

Ophthalmology Clinic,

Military Institute of Aviation Medicine, Warsaw

01-755 Warszawa, ul. Krasińskiego 54/56

e-mail: marekprost@wp.pl

ORCID

Marek E. Prost - ID - http://orcid.org/0000-0002-5620-4171

\section{References}

1. Ta CN, Chang RT, Singh K et al. Antibiotic resistance patterns of ocular bacterial flora. Ophthalmology. 2003; 110: 1946-51.

2. Petricek I, Prost M, Popova A. The differential diagnosis of red eye: A survey of medical practitioners from Eastern Europe and the Middle East. Ophthalmologica. 2006; 220: 229-37.

3. Filipek B, Prost M. Leki stosowane w leczeniu chorób infekcyjnych oczu. In: Prost M, Jachowicz R, Nowak JZ (ed). Kliniczna farmakologia okulistyczna, $2^{\text {nd }}$ ed. Elsevier, Wrocław 2016.

4. Oksuz L, Ozbilen KT. A Three-Year Analysis of Ocular Infections in a Tertiary Care University Hospital in Turkey. Clin Lab. 2021; 67: 9-10.

5. Prost M. Podstawy antybiotykoterapii schorzeń powierzchni oka. OphthaTherapy. Terapie w Okulistyce. 2014, 1: 26-32.

6. Hauser AR. Antibiotic basics for clinicians: The ABCs of choosing the right antibacterial agent. Lippincott Williams \& Wilkins, Philadelphia 2012.

7. Blondeau JM. Fluoroquinolones: Mechanism of action, classification, and development of resistance. Surv Ophthalmol. 2004; 49(suppl 2): S73-S8.

8. Wagner RS, Abelson MB, Shapiro A et al. Evaluation of moxifloxacin, ciprofloxacin, gatifloxacin, ofloxacin, and levofloxacin concentration in human conjunctival tissue. Arch Ophthalmol. 2005; 123: 182-3.

9. Stewart WC, Crean CS, Zink RC et al. Pharmacokinetics of azithromycin and moxifloxacin in human conjunctiva and aqueous humour during and after the approved dosing regimens. Am J Ophthalmol. 2010; 150: 744-51. 
10. Katz HR, Masket S, Lane SS et al. Absorption of topical moxifloxacin ophthalmic solution into human aqueous humour. Cornea. 2005; 24: 955-8.

11. Kim DH, Stark WJ, O'Brien TP et al. Aqueous penetration and biological activity of moxifloxacin $0,5 \%$ ophthalmic solution and gatifloxacin solution in cataract surgery patients. Ophthalmology. 2005; 112: 1992-6.

12. Lai WW, Chu KO, Chan KP et al. Differential aqueous and vitreous concentrations of moxifloxacin and ofloxacin after topical administration one hour before vitrectomy. Am J Ophthalmol. 2007; 144: 315-8.

13. Ong-Tone L. Aqueous humor penetration of gatofloxacin and moxafloxacin eyedrops given be different methods before cataract surgery. J Cataract Refract Surg. 2007; 33: 59-62.

14. McCulley JP, Caudle D, Aronowicz JD et al. Fourth-generation fluoroquinolone penetration into the aqueous humor in humans. Ophthalmology. 2006; 113: 955-9.

15. Yagci R, Oflu Y, Dincel A et al. Penetration of second-, third-, and fourth-generation of topical fluoroquinolone into aqueous and vitreous humour in a rabbit endophthalmitis model. Eye. 2007; 21: 990-4.

16. Yamada M, Mochizuki H, Yamada K et al. Aqueous humor levels of topically applied levofloxacin, norfloxacin and lomefloxacin in the same human eyes. J Cataract Refract Surg. 2003; 29: 1771-5.

17. Hwang DG. Fluoroquinolone resistance in ophthalmology and the potential role for newer ophthalmic fluoroquinolones. Surv Ophthalmol. 2004; 49(suppl 2): S79-S83.

18. Prost M, Semczuk K. Antybiotykooporność szczepów bakteryjnych worka spojówkowego u dzieci. Klin Oczna. 2005; 107: 418-20.

19. Alabaiad CR, Miller D, Schiffman JC et al. Antimicrobial resistance profiles of ocular and nasal flora in patients undergoing intravitreal injections. Am J Ophthalmol. 2011; 152: 999-1004.

20. Fintelmann RE, Hoskins EN, Lietman TM et al. Topical fluoroquinolone use as a risk factor for in vitro fluoroquinolone resistance in ocular cultures. Arch Ophthalmol. 2011; 129: 399-402.

21. Kim SJ, Toma HS. Ophthalmic antibiotics and antimicrobial resistance: A randomized, controlled study of patients undergoing intravitreal injections. Ophthalmol. 2011; 118: 1358-63.

22. Deschênes J, Blondeau J. Besifloxacin in the management of bacterial infections of the ocular surface. Can J Ophthalmol. 2015; 50: 184-91.

23. Keen $\mathrm{M}$, Thompson M. Treatment of Acute Conjunctivitis in the United States and Evidence of Antibiotic Overuse: Isolated Issue or a Systematic Problem? Ophthalmology. 2017; 124: 1096-8.

24. Dortonne I, Colmenares, P, Lyford T et al. Evaluation of infectious conjunctivitis by clinical evaluation and novel diagnostics. JUCM. 2019; 10: $11-5$.

25. Gominet M, Seghezzi N, Mazodier P. Acyl depsipeptide (ADEP) resistance in Streptomyces. Microbiology. 2011; 157: 2226-34.

Conflict of interest:

None.

Financial support:

None.

Ethics:

The content presented in the article complies with the principles of the Helsinki

Declaration, EU directives and harmonized requirements for biomedical journals. 